\title{
Penerapan teknologi budidaya bunga matahari di kelompok tani hortikultura
}

\section{Titin Sumarni ${ }^{1}$, Kartika Yurlisa ${ }^{2 *}$, Husni Thamrin Sebayang ${ }^{3}$, Karuniawan Puji Wicaksono ${ }^{4}$, Agung Nugroho ${ }^{5}$}

1Universitas Brawijaya, Malang, Indonesia, email:tns_fpub@yahoo.com

2Universitas Brawijaya, Malang, Indonesia, email: kartikayurlisa2@gmail.com

3Universitas Brawijaya, Malang, Indonesia, email: husni_thsby@yahoo.co.id

${ }^{4}$ Universitas Brawijaya, Malang, Indonesia, email: karuniawanw@gmail.com

${ }^{5}$ Universitas Brawijaya, Malang, Indonesia, email: nugroho.fp@ub.ac.id

*Koresponden penulis

\begin{tabular}{|c|c|}
\hline Info Artikel & Abstract \\
\hline $\begin{array}{l}\text { Diajukan: 2021-07-08 } \\
\text { Diterima: 2021-12-01 } \\
\text { Diterbitkan: 2021-12-23 } \\
\text { Keywords: } \\
\text { empowerment; cultivation; } \\
\text { sunflowers; Bokor; } \\
\text { Tumpang } \\
\text { Kata Kunci: } \\
\text { pemberdayaan; budidaya; } \\
\text { bunga matahari; Bokor; } \\
\text { Tumpang } \\
\begin{array}{l}\text { W } \\
\text { Check for } \\
\text { updates }\end{array}\end{array}$ & $\begin{array}{l}\text { This community service project involves training farmer group in } \\
\text { Bokor Village. This project seeks to develop skills in sunflower plant } \\
\text { cultivation, and provides understanding and increases community } \\
\text { participation in sunflower plant cultivation. The initiative is driven by } \\
\text { the village's growth objective toward becoming a tourism destination. } \\
\text { Sunflowers can enhance the attractiveness and aesthetic value of } \\
\text { the village surroundings, hence attracting tourists. This has the } \\
\text { potential to improve people's welfare and create new jobs indirectly. } \\
\text { The service project has been carried out from July - November } 2020 \\
\text { in Bokor Village, Malang Regency. The implementation method is } \\
\text { Training of Trainer (TOT). The stages of the service method carried } \\
\text { out include planning, preparation, implementation of activities, } \\
\text { monitoring and, evaluation. The community service team monitored } \\
\text { online and offline/went directly to the field, to see the condition of the } \\
\text { plants and to communicate as well as to discuss with farmer } \\
\text { representative. At the end of the service project, the service team } \\
\text { also donated high-quality sunflower seeds. The results of the service } \\
\text { project are that there has been an increase in technological skills for } \\
\text { sunflower plant cultivation in farmer group in Bokor Village, } \\
\text { understanding and community participation in sunflower plant } \\
\text { cultivation plants has also increased. }\end{array}$ \\
\hline Lisensi: $c c-b y$-sa & Abstrak \\
\hline $\begin{array}{l}\text { Copyright @ } 2022 \text { Titin Sumarni, } \\
\text { Kartika Yurlisa, Husni Thamrin } \\
\text { Sebayang, Karuniawan Puji } \\
\text { Wicaksono, Agung Nugroho }\end{array}$ & $\begin{array}{l}\text { Program pengabdian masyarakat ini berupa pelatihan teknologi } \\
\text { budidaya tanaman bunga matahari di kelompok tani Desa Bokor. } \\
\text { Kegiatan ini bertujuan untuk meningkatkan keterampilan teknologi } \\
\text { budidaya tanaman bunga matahari di kelompok tani, dan } \\
\text { memberikan pemahaman dan meningkatkan partisipasi masyarakat } \\
\text { untuk membudidayakan tanaman bunga matahari. Program tersebut } \\
\text { dilatarbelakangi oleh rencana desa untuk mengembangkan desa ke } \\
\text { arah desa wisata. Keberadaan bunga matahari dapat menambah } \\
\text { daya tarik dan nilai estetika lingkungan, sehingga dapat menarik } \\
\text { wisatawan untuk berkunjung ke desa. Hal ini secara tidak langsung } \\
\text { dapat meningkatkan kesejahteraan masyarakat dan menciptakan } \\
\text { lapangan kerja baru. Kegiatan pengabdian telah dilaksanakan dari } \\
\text { bulan Juli - November } 2020 \text { di Desa Bokor Kabupaten Malang. } \\
\text { Metode pelaksanaan adalah metode Training of Trainer (TOT). } \\
\text { Tahapan metode pengabdian yang dilakukan meliputi perencanaan, } \\
\text { persiapan, pelaksanaan kegiatan, monitoring dan evaluasi. Tim }\end{array}$ \\
\hline
\end{tabular}


pengabdian masyarakat melakukan monitoring secara daring dan luring/langsung turun ke lapangan, untuk melihat langsung kondisi tanaman dan berkomunikasi sekaligus berdiskusi dengan perwakilan petani. Di akhir kegiatan pengabdian, tim pengabdian juga melakukan pemberian bantuan benih tanaman bunga matahari yang bermutu tinggi. Hasil program pengabdian yaitu telah meningkatnya keterampilan teknologi budidaya tanaman bunga matahari di kelompok tani Desa Bokor, pemahaman dan partisipasi masyarakat untuk membudidayakan tanaman bunga matahari juga meningkat.

Cara mensitasi artikel:

Sumarni, T., Yurlisa, K., Sebayang, H. T., Wicaksono, K. P., \& Nugroho, A. (2022). Penerapan teknologi budidaya bunga matahari di kelompok tani hortikultura. Jurnal Inovasi Hasil Pengabdian Masyarakat (JIPEMAS), 5(1), 45-57. https://doi.org/10.33474/jipemas.v5i1.11460

\section{PENDAHULUAN}

Kelompok tani Desa Bokor berlokasi di Kecamatan Tumpang, Kabupaten Malang, Provinsi Jawa Timur. Mata pencarian utama penduduk desa adalah petani. Bidang pertanian memberikan sumbangan besar dalam perekonomian Desa Bokor. Mayoritas lahan digunakan sebagai lahan pertanian, baik yang berupa milik sendiri maupun yang sewa. Komoditas tanaman yang umum ditanam adalah padi, jagung dan sayur mayur. Setelah tanaman dipanen, hasil produksi langsung dijual ke pasar (Pemerintah Desa Bokor, 2014).

Desa Bokor adalah salah satu desa yang berpotensi untuk dikembangkan sebagai desa wisata. Desa wisata merupakan desa yang memiliki karakteristik khusus baik berupa tradisi dan budaya yang terjaga keasliannya, makanan khas, sistem pertanian dan sistem sosial maupun kelestarian lingkungan sehingga dapat dijadikan sebagai daerah tujuan wisata (Zakaria dan Suprihardjo, 2014). Desa Bokor memiliki keunikan dan daya tarik tersendiri yakni daerah pertanian yang dikelilingi alam pedesaan, dan letak desa yang strategis, di jalur menuju gunung Bromo melalui Tumpang. Ditinjau dari letak dan pemandangan alam Desa Bokor maka desa tersebut berpotensi besar untuk dikembangkan sebagai agrowisata.

Bidang pertanian merupakan sektor utama di Desa Bokor, dengan adanya perencanaan untuk pengembangan bidang pariwisata maka arah pembangunan desa yang tepat adalah melalui konsep agrowisata. Agrowisata adalah jenis wisata minat khusus yang mendayagunakan pertanian sebagai objek utamanya (Wihananto et al., 2016). Sebagai langkah awal pengembangan agrowisata, desa bermaksud untuk mengembangkan wisata bunga matahari.

Pemilihan komoditas bunga matahari juga dilatarbelakangi oleh profil dan kondisi lingkungan Desa Bokor yang sesuai dengan syarat tumbuh tanaman tersebut. Selain keindahan bunganya, biji tanaman bunga matahari diketahui memiliki banyak manfaat bagi tubuh manusia. Bunga dapat dikembangkan menjadi bisnis tanaman hias, dan bijinya dapat diolah menjadi makanan (kuaci). Bunga matahari merupakan salah satu jenis tanaman potensial di Indonesia sebagai tanaman hias serta tanaman produksi biji kuaci (Audina et al., 2017). Usaha budidaya tanaman bunga matahari mempunyai prospek ke depan yang cerah, karena permintaan biji bunga matahari terbesar 
datang dari industri kuaci, baik yang diolah menjadi makanan atau minyak murni biji bunga matahari.

Nama botani bunga matahari yaitu Helianthus annuus L., famili tanaman ini adalah Asteraceae (Saini dan Sharma, 2011). Tanaman tahunan ini mempunyai batang tegak, kokoh, dan kasar, dan memiliki tinggi mencapai 1-3 meter. Tanaman bunga matahari dapat tumbuh dengan baik pada suhu berkisar $20-25^{\circ} \mathrm{C}$. Pada suhu di atas $25^{\circ} \mathrm{C}$ dapat menyebabkan berkurangnya produksi minyak pada biji matahari sedangkan pada suhu yang sangat dingin dapat menghambat semua fase pertumbuhan bunga matahari (FernándezLuqueño et al., 2014).

Benih bunga matahari dengan kandungan minyak yang terdapat di dalamnya, menyebabkan rendahnya daya simpan benih akibat kimia lipid dalam benih lebih mudah terdegradasi (Lima et al., 2014). Penyimpanan benih bunga matahari yang sesuai menurut pendapat Burrill (2010), dapat dilakukan pada suhu di bawah $20^{\circ} \mathrm{C}$, dengan kandungan minyak benih sebesar $40 \%$ dan tingkat kelembapan kurang dari 9\%. Umur penyimpanan benih bunga matahari juga dapat ditingkatkan dengan perlakuan pemberian kunyit.

Budidaya tanaman hias mampu meningkatkan nilai estetika lingkungan, mengurangi polusi udara, hingga dapat menyediakan tanaman berkhasiat obat bagi keluarga. Budidaya tanaman hias juga bernilai ekonomi dan dapat menjadi sumber pendapatan bagi masyarakat (Widyastuti, 2018). Bunga matahari dengan karakteristik batang pendek umumnya dimanfaatkan sebagai bunga potong, sedangkan yang memiliki banyak kepala bunga dimanfaatkan sebagai bunga pot (Short et al., 2017). Budidaya tanaman bunga matahari tidaklah sulit, namun yang menjadi tantangan bagi pembudidaya adalah bagaimana tanaman bunga matahari tersebut mampu menghasilkan biji yang sempurna. Untuk menghasilkan biji bunga matahari yang optimal diperlukan pemeliharaan, perawatan dan pemupukan yang tepat. Oleh karena itu, kelompok tani Desa Bokor harus mempunyai keterampilan teknis budidaya tanaman bunga matahari.

Kegiatan pengabdian masyarakat ini ditujukan untuk mendapatkan solusi permasalahan yang dialami oleh kelompok tani Desa Bokor yaitu minimnya pengetahuan dan keterampilan dalam membudidayakan bunga matahari. Fokus pengabdian masyarakat yaitu pelatihan pembudidayaan bunga matahari pada kelompok tani Desa Bokor. Kelompok tani dan masyarakat Desa Bokor pada umumnya dapat bekerja sama dengan baik dalam kegiatan yang dilaksanakan, terutama kegiatan untuk pengembangan kesejahteraan mereka. Hal tersebut menjadi alasan yang mendasari pemilihan kelompok tani Desa Bokor sebagai subyek pengabdian.

Pemberdayaan masyarakat adalah usaha yang bertujuan untuk menyejahterakan masyarakat. Pemberdayaan masyarakat dilakukan dengan mengembangkan potensi yang ada dalam masyarakat sehingga tercipta kemandirian dalam masyarakat (Almasri dan Deswimar, 2014). Konsep pemberdayaan masyarakat tidak bertujuan untuk membuat masyarakat menjadi tergantung pada bantuan dari pihak lain. Tetapi masyarakat menjadi subjek (pelaku) dari pengabdian masyarakat itu sendiri. 
Berdasarkan latar belakang tersebut diatas, pengabdian masyarakat ini berusaha untuk mengenalkan teknologi budidaya bunga matahari agar dapat memberdayakan kelompok tani sehingga mendukung pengembangan Desa Bokor menuju desa wisata. Tujuan dari kegiatan pengabdian masyarakat yaitu: (a) meningkatkan keterampilan teknologi budidaya tanaman bunga matahari bagi kelompok tani dalam mendukung rencana desa menuju desa wisata, (b) memberikan pemahaman dan meningkatkan partisipasi masyarakat untuk membudidayakan tanaman bunga matahari. Kegiatan pengabdian masyarakat ini diharapkan dapat memberikan dampak positif yaitu meningkatkan nilai tambah baik secara ekonomi maupun lingkungan bagi Desa Bokor.

\section{METODE PELAKSANAAN}

Lokasi pengabdian dilaksanakan di Desa Bokor Kecamatan Tumpang Kabupaten Malang dengan pertimbangan bahwa wilayah tersebut merupakan wilayah yang strategis untuk mengembangkan kawasan "agrowisata"dan pembudidayaan tanaman bunga matahari. Pengabdian dilaksanakan pada bulan Juli sampai dengan November 2020. Sasaran kegiatan pengabdian ini adalah kelompok tani Desa Bokor, Kecamatan Tumpang, Kabupaten Malang. Luaran program pengabdian ini yaitu penerapan teknologi budidaya tanaman bunga matahari yang tepat. Luaran tersebut diharapkan dapat mendukung rencana desa menuju desa wisata.

Pemilihan metode pengabdian yang tepat akan mewujudkan luaran yang efektif serta efisien. Salah satu ciri metode pengabdian masyarakat yang tepat yaitu teknologi budidaya yang diajarkan pada kegiatan pengabdian dapat diterapkan dengan baik dan memberikan manfaat untuk para peserta. Tahapan metode pengabdian yang dilakukan meliputi perencanaan, persiapan, pelaksanaan kegiatan, monitoring dan evaluasi. Pada tahap perencanaan terdiri dari penyusunan tujuan yang dapat diukur, memilih metode pelaksanaan kegiatan dan sarana prasarana transfer teknologi. Pada tahap persiapan, tim pengabdian mengajukan kerjasama dan perizinan kepada Kepala Desa Bokor, serta meminta masukan serta saran terkait kuantitas peserta, tempat dan waktu kegiatan. Juga dilakukan persiapan peralatan dan perlengkapan yang diperlukan seperti alat dan bahan bercocok tanam, transportasi, dokumentasi dan lain sebagainya. Pada tahapan pelaksanaan kegiatan dilakukan metode diseminasi yaitu ceramah, diskusi, dan penayangan video. Setelah itu dilakukan pendampingan secara daring dan luring. Evaluasi dilakukan setiap akhir kegiatan. Yang bertujuan sebagai tindakan koreksi dan perbaikan untuk program pengabdian selanjutnya. Tahapan-tahapan kegiatan program pengabdian disajikan pada Gambar 1.

Kegiatan pengabdian masyarakat ini menggunakan dua macam tanaman bunga matahari yaitu tanaman bunga matahari varietas IPB BM-1 dan tanaman bunga matahari berlabel dagang Tuwok. Benih IPB BM-1 dan benih Tuwok memiliki karakteristik biji dan morfologi tanaman yang berbeda. Untuk benih IPB BM-1 mempunyai biji berukuran kecil dan cocok untuk 
dibudidayakan di pekarangan. Sedangkan benih Tuwok mempunyai biji berukuran besar dan cocok untuk produksi kuaci kupas.

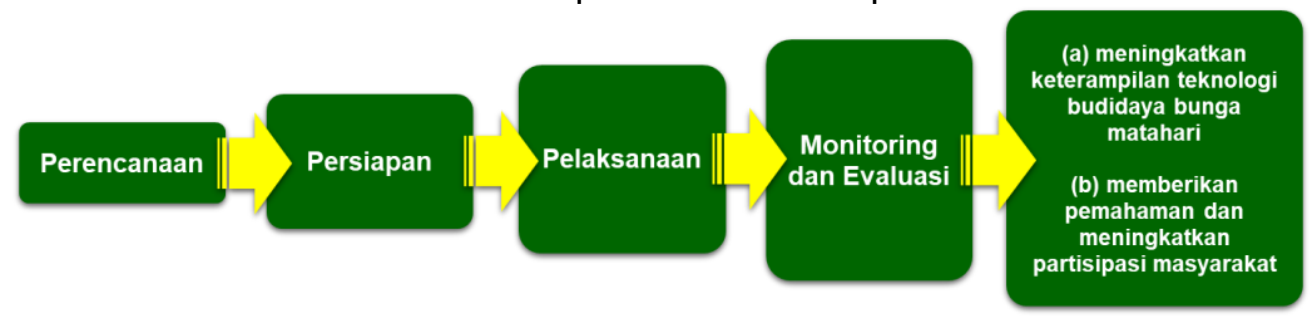

Gambar 1. Alur kegiatan pengabdian

\section{HASIL DAN PEMBAHASAN}

Kegiatan pengabdian masyarakat diawali dengan tahap perencanaan yaitu penyusunan tujuan, pemilihan metode pelaksanaan, membuat rencana kegiatan, analisis kebutuhan mitra, observasi dan wawancara dengan tokoh masyarakat. Kegiatan perencanaan telah dilaksanakan pada tanggal 1 Juli 2020. Analisis kebutuhan mitra dilakukan untuk mengkaji potensi, lingkungan, dan sosial budaya kawasan Desa Bokor. Hasil analisis sebagai berikut: peran serta masyarakat sudah cukup baik dalam mendukung program pengembangan Desa Bokor menuju desa wisata, belum optimalnya pembangunan sarana dan prasarana, seperti tersedianya tempat parkir kendaraan di sekitar area pemancingan, belum terealisasinya pengembangan areal wisata bunga, belum ada kegiatan rutin yang mengundang wisatawan tertarik untuk datang ke desa tersebut. Kemudian dilanjutkan dengan tahap persiapan yaitu pengajuan kerjasama dan perizinan kepada Kepala Desa Bokor, serta permohonan masukan dan saran terkait pelaksanaan dan persiapan alat, bahan, tempat dan kebutuhan-kebutuhan lain untuk pelaksanaan pengabdian masyarakat.

Kegiatan diseminasi telah dilaksanakan di balai Desa Bokor pada hari rabu, tanggal 22 Juli 2020 dari pukul 13.00-17.00 WIB. Metode pelaksanaan/diseminasi yang dipilih adalah metode Training of Trainer (TOT). Metode ini merupakan model pengembangan sumber daya manusia yang sering digunakan dan dipilih berkaitan dengan pembatasan jumlah petani yang diundang terkait dengan situasi pandemi coronavirus disease 19 yang sedang terjadi pada waktu tersebut. Dengan metode TOT diharapkan petani yang diundang pada saat pelatihan akan mentransfer ilmunya ke petani lain yang tidak hadir pada acara pengabdian. Sehingga dampak program pengabdian menjadi luas. Peserta pengabdian yang hadir sejumlah 16 orang, yang terdiri dari perangkat desa, kelompok tani, tokoh masyarakat serta tokoh pemuda. Berdasarkan jumlah kehadiran para peserta yang tinggi mengindikasikan keberhasilan program pengabdian sesuai dengan yang direncanakan. Strategi penyampaian materi pengabdian diawali dengan refleksi dan evaluasi pada pengetahuan dan sikap peserta terkait budidaya tanaman bunga matahari, dan ditayangkan juga video budidaya tanaman bunga matahari, pemberian materi dengan metode ceramah, dan ditutup dengan kegiatan diskusi. 
Kepala Desa, Arianto dalam sambutannya menyampaikan bahwa pembangunan Desa Bokor diarahkan untuk menuju kampung ijo, yang bertujuan untuk pengembangan desa wisata. Pembangunan desa tahun kedua diarahkan pada wilayah pertanian, yang telah didukung oleh usaha pemuda desa berupa kolam pemancingan. Keberadaan tanaman hias bunga matahari di lahan pertanian juga akan menambah nilai estetika dan keindahan desa.

Perwakilan Laboratorium Sumber Daya lingkungan FP UB, Dr. Ir. Sitawati, MS. dalam sambutannya menjelaskan bahwa selain sebagai tanaman hias, bunga matahari juga dapat berfungsi sebagai tanaman refugia. Tanaman refugia ialah tanaman yang memiliki bunga yang menjadi habitat serangga karena dapat menyediakan makanan yang dibutuhkan serangga yaitu nektar dan madu. Jumlah musuh alami dapat ditingkatkan dengan cara menyediakan tempat hidup dan makanan untuk keberlangsungan hidup musuh alami, sehingga tanaman refugia di sekitar pertanaman dapat menjadi habitat alternatif predator serta parasitoid (Keppel et al., 2012). Tanaman hias tersebut bisa ditanam bersama dengan tanaman sayuran untuk mengurangi intensitas serangan hama dan penyakit ke tanaman utama. Tanaman bunga matahari selain berfungsi estetika, juga mempunyai nilai ekonomis yaitu biji bunga yang dapat dipanen dan diproses lebih lanjut menjadi kuaci.

Penyampaian materi dengan topik: "Teknologi Budidaya Bunga Matahari" disampaikan oleh narasumber Dr. Noer Rahmi Ardiarini, SP., MSi. Narasumber merupakan pemulia tanaman FP UB yang telah banyak meneliti tanaman bunga matahari. Materi diseminasi terdiri dari beberapa bagian yaitu: pengenalan akan bunga matahari, pengenalan macam benih, teknik penyemaian dan pelaksanaan atau praktek penanaman bunga matahari. Narasumber menyarankan untuk dilakukan perencanaan mengenai pola tanam tanaman bunga matahari. Apakah di masa yang akan datang, tanaman bunga matahari akan ditumpangsarikan. Tanaman bunga matahari dapat ditumpangsarikan dengan komoditas tanaman apa dan seterusnya. Tanaman bunga matahari bisa ditumpangsarikan dengan dengan tanaman jagung, tanaman sayuran atau komoditas tanaman lainnya. Tumpangsari tanaman bunga matahari dengan tanaman jagung atau kacang tunggak menurut pendapat Amujoyegbe et al., (2013) mempunyai efisiensi penggunaan lahan yang ditunjukkan dengan nilai LER (Land Equivalent Ratio) lebih dari 1. Hal ini menunjukkan sistem tumpangsari diantara tanaman bunga matahari dengan tanaman jagung atau kacang tunggak layak untuk diterapkan. Pemanfaatan tanaman bunga matahari yang ditanam dengan tanaman bunga kertas, tanaman wijen dan kenikir sebagai tanaman refugia pada lahan padi dapat berfungsi sebagai habibat musuh alami sehingga dapat menekan intensitas hama padi (Sakir dan Desinta, 2019).

Tanaman bunga matahari juga toleran terhadap pemupukan dan menyesuaikan dengan kondisi lahan tempat tumbuh. Kebutuhan pupuk $\mathrm{N}$ pada tanaman bunga matahari hanya sekitar $56 \mathrm{~kg} \mathrm{ha}^{-1}$ (Debaeke et al., 2017). Kunci pembudidayaan tanaman bunga matahari adalah memberikan pengairan secukupnya, tidak berlebihan tetapi jangan sampai kekurangan air. 
Pemberian air yang tepat pada tanaman bunga matahari dapat dilakukan pada saat tanaman berumur 30, 45, 60 dan 75 hst sehingga menghasilkan biji bunga matahari yang bernilai ekonomi tinggi (Buriro et al., 2015). Peserta juga diberi kesempatan untuk bertanya dan berdiskusi mengenai isi materi. Diskusi dilakukan agar dapat memberikan pemahaman materi yang lebih baik. Untuk mendukung kegiatan pengabdian, juga dilakukan pemberian bantuan benih dan peralatan penyemaian kepada Kelompok Tani Desa Bokor. Dokumentasi kegiatan diseminasi disajikan pada Gambar 2.

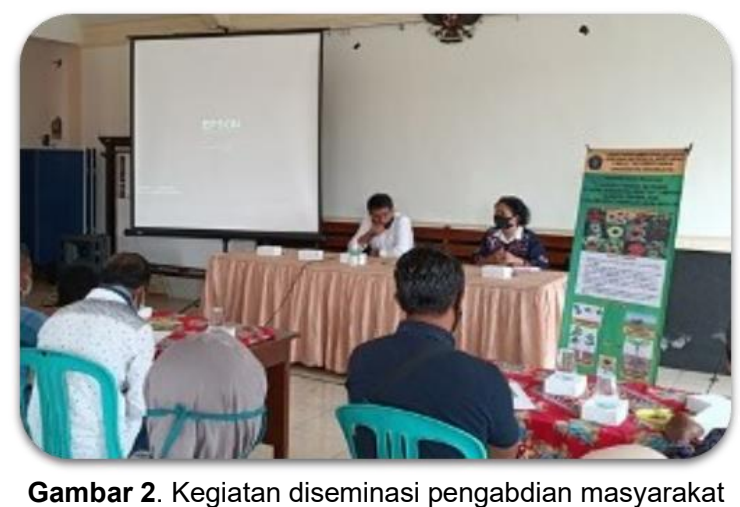

Satu minggu setelah kegiatan diseminasi, dilakukan kegiatan penyemaian benih bunga matahari yang dilakukan kelompok tani secara mandiri. Kegiatan pengabdian masyarakat ini menggunakan dua macam tanaman bunga matahari yaitu tanaman bunga matahari varietas IPB BM-1 dan tanaman bunga matahari berlabel dagang Tuwok. Kedua macam benih sudah diuji daya berkecambahnya di awal kegiatan pengabdian masyarakat. Hasil uji menunjukkan daya berkecambah yang tinggi serta pertumbuhan yang seragam. Dalam konteks produksi tanaman, benih diharapkan mempunyai mutu yang tinggi, karena benih harus dapat menghasilkan tanaman yang mempunyai daya hasil maksimum (Ningsih et al., 2018). Kualitas mutu benih menentukan keberhasilan budidaya tanaman.

Bibit bunga matahari tumbuh dengan baik di persemaian. Dari bibit yang disemai, kelompok tani merencanakan pembagian bibit-bibit tersebut ke rumah-rumah warga, masing-masing rumah akan mendapat 2-3 bibit. Dengan tujuan agar warga desa dapat melakukan budidaya tanaman bunga matahari secara mandiri di rumah masing-masing. Hal ini sekaligus menambah nilai estetika dan keindahan Desa Bokor. Keberadaan bibit ini menarik perhatian pengunjung yang mengunjungi balai desa, sehingga sejumlah bibit diminta dan dibawa pulang oleh pengunjung, dengan tujuan untuk dibudidayakan di tempat tinggal masing-masing. Dokumentasi kegiatan persemaian benih bunga matahari disajikan pada Gambar 3. 


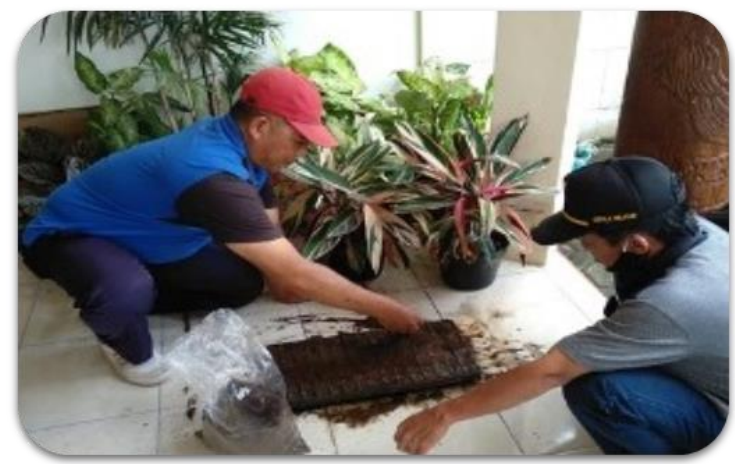

Gambar 3. Kegiatan persemaian benih bunga matahari

Kegiatan pendampingan dilakukan secara daring dan luring. Pendampingan secara daring dilakukan dalam bentuk komunikasi melalui daring (menggunakan aplikasi WhatsApp) untuk memastikan penerapan teknologi budidaya bunga matahari sudah dijalankan dengan tepat dan baik oleh kelompok tani. Selain dilakukan monitoring secara daring, tim pengabdian masyarakat juga melakukan pendampingan secara luring /langsung turun ke lapangan, untuk melihat langsung kondisi tanaman dan berkomunikasi sekaligus berdiskusi dengan perwakilan petani. Pendampingan luring dilakukan dua kali yaitu pada waktu fase vegetatif tanaman (30 Agustus 2020) dan fase generatif tanaman (4 Oktober 2020). Dokumentasi kegiatan pendampingan disajikan pada Gambar 4.

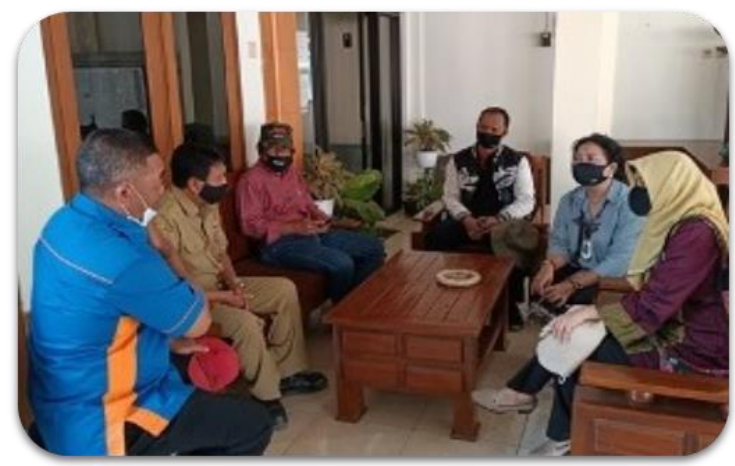

Gambar 4. Pendampingan kepada mitra yang dilakukan secara luring

Kelompok tani Desa Bokor telah mencoba untuk menyemai kembali benih bunga matahari dengan menggunakan benih bunga matahari lokal. Dari 2 macam benih bunga matahari lokal yang ditanam, yang berbiji kecil dan berbiji besar telah disemai sejumlah 100 benih, jenis benih yang tumbuh hanya yang berbiji kecil. Pertumbuhan benih bunga matahari lokal pun terlihat tidak seragam. Ketidakseragaman pertumbuhan benih bunga matahari dapat disebabkan oleh ketidaksesuaian lingkungan tumbuh benih. Perkecambahan benih tanaman bunga matahari sangat dipengaruhi oleh suhu dan ketersediaan air, pada suhu $25-35^{\circ} \mathrm{C}$ dengan perlakuan pemberian air setiap 
hari menghasilkan perkecambahan benih bunga matahari yang baik dan sehat (Shaheen et al., 2014). Selain hal tersebut, persentase perkecambahan dari benih bunga matahari juga dapat dipengaruhi oleh faktor genotip, dan juga sangat ditentukan oleh interaksi diantara genotip dan lingkungan tumbuh (Radić et al., 2020). Perlakuan perendaman terhadap benih bunga matahari ke dalam GA3 berkonsentrasi 500 ppm dapat meningkatkan persentase perkecambahan sebesar $80 \%$ (Adams dan Tebeest, 2016). Dokumentasi pertumbuhan bibit bunga matahari lokal disajikan pada Gambar 5.

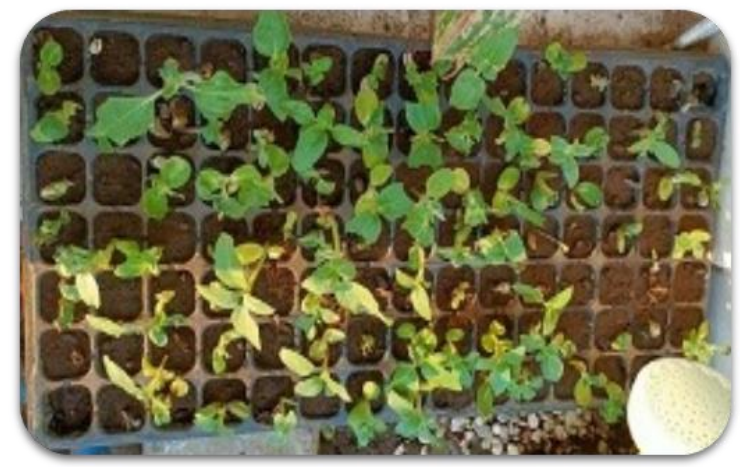

Gambar 5. Pertumbuhan benih tanaman bunga matahari lokal yang tidak seragam

Merespon permasalahan mitra pengabdian masyarakat diatas, maka tim pengabdian memberikan bantuan benih bunga matahari yang bermutu tinggi. Benih yang diberikan adalah benih IPB BM-1 produksi Benih Dramaga dan benih Tuwok produksi CV Sastra Bina Jawa Timur. Dokumentasi kegiatan pemberian bantuan benih bunga matahari disajikan pada Gambar 6 . Dokumentasi pembudidayaan tanaman bunga matahari disajikan pada Gambar 7.

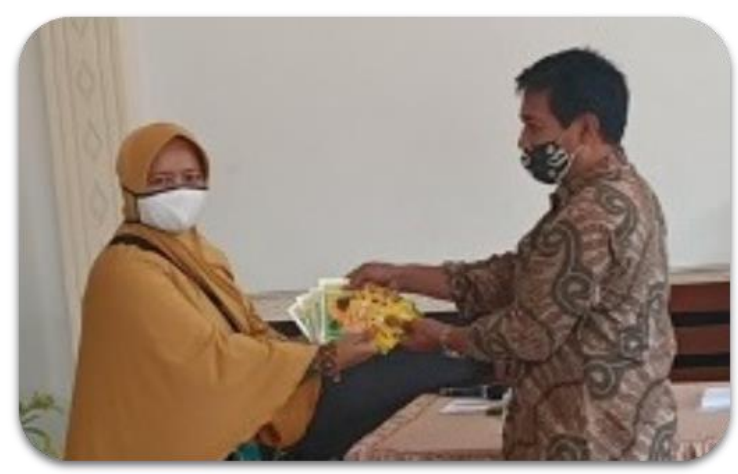

Gambar 6. Kegiatan pemberian bantuan benih 


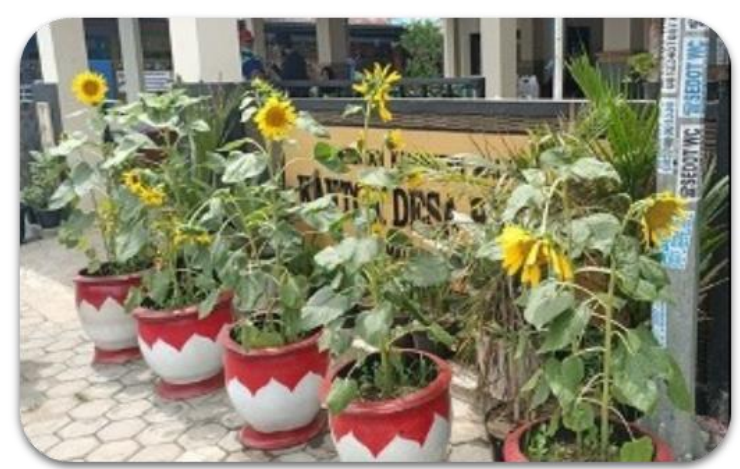

Gambar 7. Pembudidayaan tanaman bunga matahari

Bokor adalah salah satu dari 15 desa yang berada di Kecamatan Tumpang, Kabupaten Malang, Propinsi Jawa Timur. Berdasarkan penelitian terhadap potensi Desa Bokor dengan menggunakan analisis Strength, Weakness, Opportunities, and Threat (SWOT) didapatkan kekuatan desa terdapat pada letak yang menguntungkan. Letak Desa Bokor berada di arah perjalanan wisata Kota Malang menuju gunung Bromo, serta memiliki kesuburan tanah yang baik. Kelemahan desa terdapat pada lokasi desa yang memanjang dan tidak melebar, sehingga berpengaruh pada komunikasi antar warga. Peluang desa terdapat pada lokasi yang strategis untuk dijadikan tempat istirahat/rest area, disebabkan banyak kendaraan yang lalu lalang melewati desa tersebut. Ancaman terdapat pada hasil pertanian yang tidak maksimal disebabkan keterbatasan lahan ('Ibad, 2020).

Letak desa yang strategis tersebut melatarbelakangi perencanaan pemerintah Desa Bokor, untuk mengarahkan desa menuju desa wisata. Pariwisata adalah salah satu segi ekonomi yang menjanjikan untuk dikembangkan dengan mengoptimalkan luas lahan yang terbatas. Pemanfaatan lahan dapat dilakukan dengan penanaman langsung di lahan dan budidaya pekarangan di pot/polibag. Pada program pengabdian kali ini kelompok tani memilih untuk pembudidayaan tanaman bunga matahari di pot yang diletakkan di kiri dan kanan jalan depan balai desa.

Kegiatan pengabdian ini secara umum dapat dianggap cukup berhasil dan tepat sasaran, karena para peserta merupakan pemangku kepentingan di desa. Bahkan di akhir acara diseminasi, Kepala Desa menginginkan program ini terus berlanjut. Jumlah peserta yang tidak mengalami pengurangan dari awal sampai akhir juga merupakan pertanda bahwa para peserta cukup tertarik dan menganggap penting kegiatan diseminasi ini.

Tantangan berikutnya dalam pembudidayaan tanaman hias adalah pemeliharaan tanaman bunga matahari yang dilakukan secara intensif. Bagi kelompok tani yang dulunya membudidayakan tanaman pangan dan sayur, hal ini merupakan sesuatu yang baru. Sehingga perlu dilakukan pengorganisasian dan penjadwalan pemeliharaan pada kelompok tani. Pernyataan ini didasarkan atas hasil pendampingan yang telah dilaksanakan. 
Dengan pemeliharaan yang optimal, diharapkan tanaman bunga matahari bisa tumbuh dan memberikan hasil yang maksimal.

Bentuk peran serta masyarakat untuk mengembangkan dan mengelola kawasan lingkungan Desa Bokor menuju desa wisata sebagai berikut: (a) peran serta masyarakat dalam pemanfaatan pekarangan rumah dan lahan tidur lainnya sebagai lahan pembudidayaan tanaman bunga matahari sudah cukup baik; (b) penataan pot bunga matahari di sepanjang jalan di depan balai Desa Bokor sebagai bentuk area percontohan pembudidayaan tanaman bunga matahari memberikan nilai estetika dan daya tarik Desa Bokor.

Hasil pendampingan ini menyarankan untuk pengembangan budidaya jenis/varietas bunga matahari yang bijinya bisa diolah lebih lanjut menjadi biji kuaci. Sehingga tanaman bunga matahari tidak hanya memberikan nilai estetika pada lingkungan, tapi juga mempunyai nilai ekonomis.

\section{KESIMPULAN}

Hasil dari program pengabdian yang telah dilaksanakan yaitu: (a) telah meningkatnya keterampilan teknologi budidaya tanaman bunga matahari di kelompok tani Desa Bokor, (b) pemahaman dan partisipasi masyarakat untuk membudidayakan tanaman bunga matahari juga meningkat. Kegiatan pengabdian masyarakat ini mampu mendukung Desa Bokor menuju desa wisata dengan pembudidayaan tanaman bunga matahari. Tim pengabdian memberikan saran untuk pengabdian masyarakat berikutnya yaitu pembudidayaan jenis/varietas tanaman bunga matahari yang biji bunga matahari bisa diolah lebih lanjut menjadi biji kuaci, sehingga tanaman bunga matahari tidak hanya memberikan nilai estetika pada lingkungan, tetapi juga memberikan nilai ekonomis.

\section{UCAPAN TERIMA KASIH}

Karya tulis ini adalah hasil dari kegiatan pengabdian kepada masyarakat yang dilaksanakan oleh tim pengabdian Laboratorium Sumber Daya Lingkungan, Jurusan Budidaya Pertanian, Fakultas Pertanian, Universitas Brawijaya. Ucapan terima kasih diucapkan kepada Badan Penelitian dan Pengabdian Masyarakat (BPPM) FP UB yang telah memfasilitasi kegiatan pengabdian ini melalui Hibah Pengabdian Masyarakat Tahun Anggaran 2020. Selain itu ucapan terima kasih juga disampaikan kepada kepada pihak-pihak yang telah banyak membantu sehingga kegiatan pengabdian ini bisa terlaksana dengan baik.

\section{DAFTAR RUJUKAN}

'Ibad, M. T. (2020). Menguak Potensi Geografis Desa Bokor Kecamatan Tumpang. Sipemas UIN Malang. https://sipemas.uinmalang.ac.id/blog/menguak-potensigeografis-desa-bokor-kecamatantumpang

Adams, R. P., \& Tebeest, A. K. (2016). The Effects of Gibberellic Acid (GA3), Ethrel, Seed Soaking and Pre-treatment Storage Temperatures on Seed Germination of Helianthus annuus and H. petiolaris. Phytologia, 98(3), 
213-218.

Almasri, \& Deswimar, D. (2014). Peran Program Pemberdayaan Masyarakat Desa Dalam Pembangunan Desa. El-Riyasah: Jurnal Kepemimpinan Dan Administrasi, 5(1), 41-52. https://doi.org/10.24014/jel.v5i1.657

Amujoyegbe, B. J., Torimiro, D. O., Tselaesele, N., \& Balole, T. V. (2013). Onfarm Evaluation of the Productivity of Intercropping Sunflower with Arable Crops Among Smallholder Farms in Nigeria and Botswana. African Journal of Agricultural Research, 8(16), 1553-1558. https://doi.org/10.5897/ajar12.2000

Audina, M., Wawan, \& Yetti, H. (2017). Pertumbuhan dan Produksi Bunga Matahari (Helianthus annus L.) Pada Dua Jenis Medium Yang Diberi Kompos Tandan Kosong Kelapa Sawit. Jom Faperta, 4(1), 1-10. https://jom.unri.ac.id/index.php/JOMFAPERTA/article/view/16750

Buriro, M., Sanjrani, A. S., Chachar, Q. I., Chachar, N. A., Chachar, S. D., Buriro, B., Gandahi, A. W., \& Mangan, T. (2015). Effect of Water Stress on Growth and Yield of Sunflower. Journal of Agricultural Technology, 11(7), 1547-1563. https://doi.org/10.37855/jah.2003.v05i01.10

Burrill, P. (2010). Safe Storage.

Debaeke, P., Bedoussac, L., Bonnet, C., Bret-Mestries, E., Seassau, C., Gavaland, A., Raffaillac, D., Tribouillois, H., Véricel, G., \& Justes, E. (2017). Sunflower crop: Environmental-friendly and agroecological. OCL Oilseeds and Fats, Crops and Lipids, 24(3). https://doi.org/10.1051/ocl/2017020

Fernández-Luqueño, F., López-Valdez, F., Miranda-Arámbula, M., RosasMorales, M., Pariona, N., \& Espinoza-Zapata, R. (2014). An Introduction To The Sunflower Crop (J. Ignacio Arribas (ed.); Issue June). Nova Science Publishers, Inc.

Keppel, G., Niel, K. P. V., Johnson, G. W., Yates, C. J., Byrne, M., Mucina, L., Schut, A. G. T., Hopper, S. D., \& Franklin, S. E. (2012). Refugia: identifying and understanding safe havens for biodiversity under climate change. Global Ecology and Biogeography, 21(4), 393-404. https://doi.org/https://doi.org/10.1111/j.1466-8238.2011.00686.x

Lima, D. de C., Dutra, A. S., Pontes, F. M., \& Bezerra, F. T. C. (2014). Storage of sunflower seeds. Journal Revista Ciencia Agronomica, 45(2), 361369. https://doi.org/10.1590/s1806-66902014000200018

Ningsih, N. N. D. R., Raka, I. G. N., Siadi, I. K., \& Wirya, G. N. A. S. (2018). Pengujian Mutu Benih Beberapa Jenis Tanaman Hortikultura yang Beredar di Bali. Agroekoteknologi Tropika, 7(1), 64-72. https://ojs.unud.ac.id/index.php/JAT/article/view/38261

Pemerintah Desa Bokor. (2014). Rencana Pembangunan Jangka Menengah Desa Tahun 2014-2019.

Radić, V., Balalić, I., Miladinov, Z., Ćirić, M., Vasiljević, M., Jocić, S., \& Marjanović-Jeromela, A. (2020). Genotype $\times$ Environment Interaction of Some Traits in Sunflower (Helianthus annuus L.) Lines. Applied Ecology and Environmental Research, 18(1), 1707-1719. https://doi.org/10.15666/aeer/1801_17071719 
Saini, S., \& Sharma, S. (2011). Helianthus annuus (ASTERACEA) : A Review. International Journal of Pharma Professional's Research 2, 4, 381-386.

Sakir, I. M., \& Desinta, D. (2019). Pemanfaatan Refugia Dalam Meningkatkan Produksi Tanaman Padi Berbasis Kearifan Lokal. Jurnal Lahan Suboptimal, 7(1), 97-105. https://doi.org/10.33230/jlso.7.1.2018.367

Shaheen, G., Khan, A. R., Khan, M. J., Gul, P., \& Ahmed, A. (2014). Effect of Abiotic Factors on Sun Flower (Helianthus annuus L.) Seed Germination, Seedling Growth and Oil Content. European Journal of Experimental Biology, 4(6), 86-89.

Short, K., Etheredge, C. L., \& Waliczek, T. M. (2017). Studying The Market Potential For Specialty Cultivars Of Sunflower Cut flowers. HortTechnology, 27(5), 611-617. https://doi.org/10.21273/HORTTECH03710-17

Widyastuti, T. (2018). Buku Tanaman Hias. CV. Mine.

Wihananto, A., Marsono, \& Kusumasari, Y. (2016). Konsep Pengembangan Desa Wisata Berbasis Agro di Kaliwungulor. Perpustakaan Universitas Gadjah Mada.

Zakaria, F., \& Suprihardjo, R. D. (2014). Konsep Pengembangan Kawasan Desa Wisata di Desa Bandungan Kecamatan Pakong Kabupaten Pamekasan. Teknik Pomits, 3(2), 245-249. https://doi.org/10.12962/j23373539.v3i2.7292 